\title{
Professional Expansion of the Educational Practitioner Based on the Knowledge Management Under the Big Data
}

\author{
Zhihong $\mathrm{Li}^{1, *}$ \\ ${ }^{I}$ Business School, Jianghan University, Wuhan, Hubei 430056, China \\ "Corresponding author. Email: linanwudingbang@163.com
}

\begin{abstract}
The quick development of the big data has brought lots of changes to the knowledge management either in the content or in the form or in the approach. The educational practitioner, as the group of the knowledge inheritor or generator, has the duty to well manage the knowledge. Many approaches can be used to carry out the knowledge management, but the professional expansion focused on the major is the most effective way for the educational practitioner since his or her job mainly relies on the major that he or she learns at school. Therefore, the paper makes an overall study of the educational practitioner's professional expansion based on the knowledge under the big data. First, it disentangles the connotation of the knowledge management, the correlative relationship between the knowledge management and the big data and the influence of the big data to the knowledge management. Then, it exposes the interaction among the educational practitioner's professional expansion, knowledge management and the big data. Next, it elaborates the necessity of the educational practitioner's professional expansion based on the knowledge management in the conditions of the big data. Finally, it proposes the relative paths to expand the educational practitioner's professional expansion able to matching the knowledge management under the big data.
\end{abstract}

Keywords: Professional expansion, Educational practitioners, Knowledge management, Big data.

\section{INTRODUCTION}

The pluralistic economic construction and the quickly advanced social development under the big data require the current educational system to be able to cultivate the skilled personnel with the compound knowledge or trans-disciplines. The educational practitioner, as being the most important participant of the educational system, ought to assume the task of fostering the needed people without doubt. To meet the social \& economic need to the compound people, the educational practitioner himself or herself first must have the ability of training the trans-disciplines people. The obtainment of such kind of ability means that an educational practitioner is obliged to extend his or her professional knowledge besides the major specialized in at school. Also, he or she should be competent to have a good control over the different disciplines or professionals in his or her teaching and researching. That's to say, he or she needs to make the expanded professional knowledge become into the capacity to cultivate the other people by way of the knowledge management.

\section{KNOWLEDGE MANAGEMENT UNDER THE BIG DATA}

\subsection{Connotation of the Knowledge Management}

The knowledge management means to the activity of planning the creation of the knowledge and its application. This knowledge may be the cognition, experience, judgement or skills, etc. that are acquired by way of learning, practice or thinking about the nature, society or human being. The knowledge management is also a system in which various information or knowledge is created, stored, accessed, renewed and shared successively so that people can inherit and use it for their selfimprovement. Since the knowledge may be visible 
or invisible, the knowledge management includes the managing of the visible knowledge and that of the invisible knowledge. The visible knowledge management refers to the planning, use and popularization, etc. of those technologies, skills, scientific principles and rules and so on recorded in various forms of documents. The invisible knowledge means the human capital stored in the people's brain or mind. The management to the invisible knowledge is a process in which the human capital is extracted or applied through a series of encouraging tools so as to serve the society or to pass to the others for the purpose of realizing its value. Either the invisible or the visible knowledge is the form to demonstrate the knowledge. They may be transformed each other. That is to say, the invisible knowledge may be transformed into the visible knowledge or the latter may be turned into the former. In the meanwhile, the process of the transformation is that of innovating and appreciating the knowledge.

First, the invisible knowledge crystallized in human body can be transformed into the visible knowledge in the form of documents, figures, videos or audios and so on when it is inspired by the social demand or natural environment. The people who hold the invisible knowledge will expressed themselves with the style suitable for themselves, for example, writing articles or teaching others, etc. while they are encouraged for different purposes. Their invisible knowledge is often the outcome that they are educated at school or experienced in the course of their growth. Owing to this process, the wisdom of the human being can be recorded and passed from generation to generation.

Then, the visible knowledge can also be transferred into the invisible knowledge. People will become intelligent after they have been educated or trained at the educational institutions or when they communicate with the other persons or have done some readings. This course, as a matter of fact, is a process of transforming the visible knowledge or information into the invisible intelligence. The most benefit brought by this stage is that people will guide their mind or conduct in a rational and smart way. This kind of transformation exerts a subtle influence on people's character and thinking and so forth. It is just this process that makes the human society highly cultivated after thousands of years.

Next, the transformation between the invisible and visible knowledge is a process of making the knowledge created and value-added. In the course of turning the invisible knowledge into the visible one, people will integrate what they have learned or experienced into the structural knowledge system either in the form of text or drawings or else so that other people can well understand and be enlightened. More importantly, people will increase their own understanding to a certain issue when they show their invisible knowledge. In this way, the transformed invisible knowledge is not equal to the initial one, because it has been increased with this integrator's intelligence. The initial invisible knowledge is appreciated in its value. At the same time, the invisible knowledge can be passed to other people by word of mouth. This way of transformation may directly leave effects on the other people and quickly shed light on them. These inspired persons may change their mode of thinking or behavior and some new thoughts or conducts will occur to them. Considered in this angle, the volume or value of the initial invisible knowledge is increased, too.

During transferring the visible knowledge into the invisible one, the initial visible knowledge will be expanded in a way of multiplier effect. Due to the fact that different people have different experiences, various grown-up backgrounds and multiple ways of thinking, etc. they will have multifarious understanding when they read or enjoy the same book or works. These varied understandings, combined with the intelligence of different persons, will become a newly created knowledge in some chance when these persons are inspired by a factor. Thus, both in volume and in value, the initial visible knowledge can be increased while it is transformed into the invisible one.

The validity of the knowledge management ought to be founded on the following principles[1]. The first one is the accumulation principle. The accumulation is the base to carry out the knowledge management. It is able to make people know what kind of knowledge they have held and how they should expand the needed knowledge during their work and life so that they can construct a complete knowledge structure. Then comes the sharing principle. As for an organization, it should open its knowledge like rules, regulations and process, etc. to its staffs so that everyone inside can learn and be guided; as for an individual, his or her human capital may fully accomplish its value only in the conditions of training the others or expressing what he or she thinks about in the style of such documents as text, diagrams or else. Next is the 
communication principle. The communication plays more and more roles in the current complex and information-jammed society either to an organization or to an individual. Among the massive volume of messages, not every message is useful to an organization or individual. Some information may be out of date; some may be like rubbish; some may be key or urgent. Unfortunately, some important messages are often hidden behind the information that seems useless in appearance. In order to better identify the valuable information, the timely communication is quite obliged so that an organization may run without obstacle or that a friendly relationship may be set up among different persons.

\subsection{Correlative Relationship Between the Knowledge Management and the Big Data}

The knowledge management refers to the process of the planning, organizing and tracing, etc. of the knowledge, the creation and application of the knowledge. The big data belong to a term in the information technology sector. The big data are often considered as the information asset with the features of large volume, fast expansion, diversified forms, high fragmentation, low density of value and live reality. The basic technology for the big data consists of the data collection, pre-processing, NoSQL data bank, data warehouse, distributive storage and machine learning and so on. The correlative relationship between the knowledge management and the big data is shown mainly as follows:

On the one hand, the big data can provide the technological support for the knowledge management either in data gathering or in data processing, etc. In this approach, the data bank for the knowledge management system is able to be set up. In this systematic data bank, the scattered information or data can be classified, recorded, integrated, accessed and renewed so as to be able to be passed, looked up and shared. On the other hand, due to their special characteristics of massive volume, low density of value, fragmentation and diversification, etc. the big data can't be processed with the general tool like common software \& hardware. A strong systematic data management tool is needed to classify and process the big data. The knowledge management, with its remarkable organizational performance, may do lots of benefits to plan and organize the massive data so as to effectively identify the valuable data among the huge amount of the scattered information \& data and to make these identified data become the useful knowledge for the social practice. Analyzed in this angle, the big data can't be separated from the knowledge management if they are applied in a valid.

\subsection{Influence on the Knowledge Management from the Big Data}

In light of the globally famous consultation institute Mckinsey \& Company, the big data are the data set with a so large scale that the traditional software can't process whether in the access, manage or in the analysis. They are characteristic of massive data scales, fast data circulation, diversified data types and intensive value. In the conditions of the big data, The object of the knowledge management becomes more and more complicated, dynamic, enormous and disorderly than before. As a result, the common tools in the data bank are unable to deal with it. This situation brings much difficulty to managing the knowledge both in the visible and in the invisible. First, the huge volume of the knowledge makes people hard to find out what they really want if they haven't mastered enough tools of the information retrieval. This requires that the knowledge management should hold strong processing tools to plan, access, renew and innovate the total system. Second, due to the diversification of the knowledge such as word documents, excels, videos, image and all sorts of soft text, the knowledge management must have sufficient approaches to process and analyze the concerned data before obtaining the wanted outcome. Third, the quick speed of the big data makes the knowledge management be in the form of dynamics. Otherwise, the knowledge management will lose its significance if it lags behind the changeability of the information. Moreover, under the big data, due to the complex of the knowledge or information, some valuable information can't be spotted by surface. It may be found only by way of the proper analyzing way. Therefore, it is essential to develop the suitable tool for the knowledge management so as to obtain the valuable content as high efficient as possible[2]. 


\section{NECESSITY OF THE} EDUCATIONAL PRACTITIONER'S PROFESSIONAL EXPANSION FROM THE KNOWLEDGE MANAGEMENT UNDER THE BIG DATA

\subsection{Contents of the Educational Practitioner's Professional Knowledge}

The educational practitioner's professional expansion refers to the process of the continuous evolution and improvement in the professional concept, professional knowledge and the professional ability, etc. Its details consist of the following aspects: first, the educational practitioner is professional individual needing continuous improving; then to the educational practitioner, the knowledge in the major is obliged while that in the minor is indispensable; next, the educational practitioner is an aggregator of multiple roles like nurturers, learners, researchers, cooperators, preachers and even actors or actress, etc. The educational practitioner's professional expansion is featured with autonomy, preference, diversification and persistence and so on. Its autonomy lies in the facts: the conditions fit for learning in the school give lots of chances to the teacher to improve himself or herself; the student whom the teacher serves is full of new ideas or knowledge, which forces the teacher to raise himself or herself to cater for the student's demand. The diversification depends on the multiple roles in his or her work, so he or she must go on with the training himself or herself in different discipline knowledge besides the major. To better meet the student's differential demands, the teacher should make him or her become either a specialist or a multiple-talented giant. The persistence means that being an educational practitioner, the teacher ought to have the perseverance of learning, learning and further learning, if he or she does not want to be knocked out in the career.

\subsection{Interaction Among the Educational Practitioner's Professional Expansion, the Knowledge Management and the Big Data}

In the conditions of the extensive application of the big data, the educational practitioner's professional knowledge expansion, the knowledge management and the big data are interacted, interaided and inter-promoted closely (see "Figure 1").

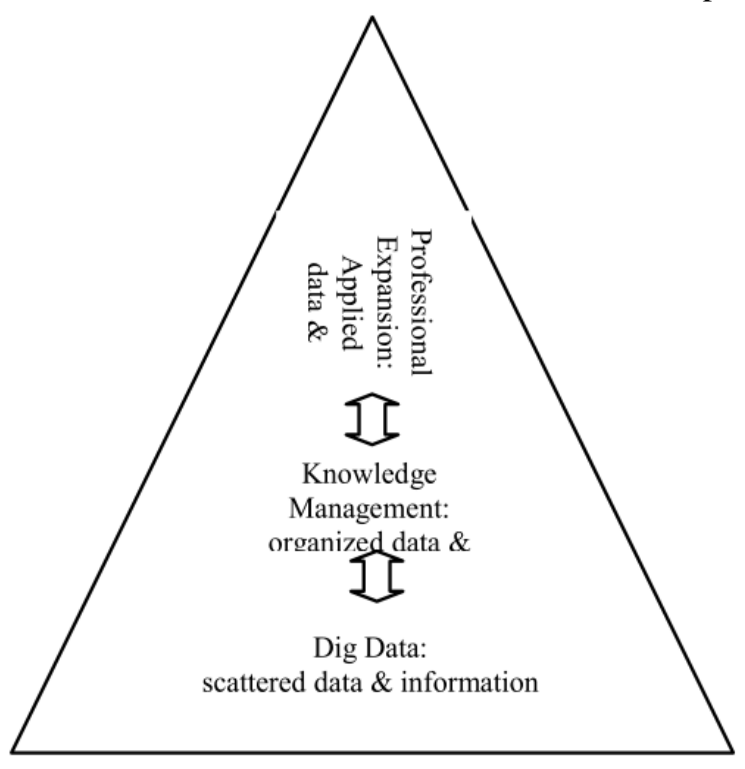

Figure 1 Interrelationship among the professional expansion of an educational practitioner, the knowledge management and the big data.

In "Figure 1", we can see that the big data, for their scattering, fragmentation and large size, etc. provide the basic sources of the data \& information and the technological support for the knowledge management and the teacher's professional expansion. Also, the knowledge management can turn the massive, complicated, fragmented data \& information into systematic, complete and correlative information \& knowledge by way of classification, selection and integration so that these 
information \& knowledge may be able to be shared and inherited. Therefore, the knowledge management has a close relationship with the big data. The former can't be separated from the latter and vice versa.

The wide use of the knowledge management and the big data has left a deep effect on the teacher's professional expansion. First, under the big data, the renewal of the knowledge has been sped up more quickly than ever before. As an owner, inheritor and creator, the teacher is bound to make an overall plan of his or her knowledge, whether it is visible or invisible, in order to pass it to the other people with the suitable approach at the right opportunity. That's to say, he or she must well manage the knowledge held by him or her by gathering, processing, sharing and generating the knowledge. The course of managing the knowledge is, as a matter of fact, a process of establishing the knowledge system and obtaining, absorbing and innovating the knowledge for a teacher. He or she must extend his or her professional knowledge around the major according to the job requirement or to the social demand. Therefore, the teacher's professional expansion is obliged on the base of the knowledge management. A valid knowledge management is the key way to a teacher's professional extension. Analyzed in another angle, the teacher's professional expansion can contribute much to the knowledge management, because a teacher, being a generator or creator, is sure to make his or her contribution to the knowledge management both in the content and in the form. During the creation or generation of the knowledge, the teacher will spend much time and energy on studying the existent knowledge in light of the work demand. Then, he or she can find out the solution to the actual issue by integrating his or her intelligent thinking about the work requirement into the existent knowledge before he or she generates the new knowledge. In a word, the process of generating a new knowledge by a teacher means a course of the transformation from the visible knowledge to invisible one to visible one again. Namely it is a course of the knowledge management.

Besides, the popularization of the big data in the educational field has further accelerated the teacher's professional expansion. The wide application of the big data in the educational system needs the teacher not only to have the competency of using the big data technological tool but also to foster the digital thinking way in his or her work. The details are reflected as follows: one is that a teacher has to master the correspondent digital software \& hardware tool so as to be able to gather the timely data \& information; the second is that, being a teacher, he or she must forge his or her digital thinking fit for the conditions of the big data in order to be sensitively aware of the professional development trend by collecting, analyzing and tracing the educational big data and adopt the concerned countermeasures to expand the professional knowledge focused on the major; the third, for a teacher, should appropriately combine the educational support technology like data mining, statistics and machine learning, etc. with the big data technology. On the one hand, such combination can help the teacher to better process and analyze the educational big data coming from the student's learning requirement, the student's score and educational appraisal, etc. and to further improve the teaching content and style; on the other hand, this combination does benefits to a better application of the big data in the educational sector.

\subsection{Necessity of the Educational Practitioner's Professional Expansion from the Knowledge Management Under the Big Data}

The wide application of the big data in all walks of people's work and life has greatly changed the content, style, approaches and scopes and so forth of the knowledge management[3]. The popularization of the big data in the knowledge management has also left deep effects on the educational practitioner who is not only the carrier or generator, but also the direct practitioner of the knowledge management. Even people can say, how deep the influence of the big data gives the knowledge management means the extent of the effect on the teacher from the knowledge management. Thus, it is quite necessary for an educational practitioner to expand his or her knowledge system according to the knowledge management under the big data. Concretely speaking, as a teacher, he or she should formulate a comprehensive plan to expand his or her invisible knowledge and visible knowledge. As for the individual, the invisible knowledge means the information existing in his or her brain or mind which consists of those contents that are informal or even hard to be clearly expressed such as experience, know-how, intuition, feeling, mode of mind, value perspectives and tacit understanding, etc. The more an individual sees or goes through, the richer his or her invisible knowledge is and the more matured he or she becomes in dealing with 
the incident met with. In the conditions of the big data, so many ways or media like internet, portable terminals, TV, QQ, Wechat and so on can be all used to expand his or her invisible knowledge as long as he or she wants. However, as a teacher, when his or her student has been well informed and intelligent in what happens with the aid of the big data, he or she is obliged to extend his or her fields of the knowledge so as to become smarter than the student, even though he or she is unwilling. Otherwise, it is difficult for him or her to cater for the student's changing demands. The visible knowledge often refers to the data recorded in the form of books, literature, journals, videos, audios, software, tables and figures, etc. All this knowledge can be passed among people or in the special place. As for a teacher, his or her visible knowledge mainly includes the systematic professional contents coming from majors and minors which he or she has acquired at school. But with the big data being widely applied, his or her existent visible knowledge system is insufficient to satisfy the need of the practical work. He or she must well manage his or her visible knowledge and keep on with learning the professional knowledge in the information technology able to fit for the requirement of the big data such as data gathering, retrieval, mining and analysis, etc so as to accomplish the teaching and researching practice.

\section{EXPANSION PATHS OF THE EDUCATIONAL PRACTITIONER'S PROFESSIONAL KNOWLEDGE BASED ON THE KNOWLEDGE MANAGEMENT UNDER THE BIG DATA}

As for an educational practitioner, he or she is obliged to expand his or her professionals around the majors in the course of the total career (see "Figure 2"). Under the big data, the social, economic and scientific \& technological development at a high speed has been putting forward more and more requirements to the skilled personnel with multiple competencies. The people with unique professional can't meet the changing needs of the society. The social demand to the compound skilled personnel requires that an educational practitioner should be competent in multiple professionals. It is an inevitable trend for a teacher to keep on with enlarging his or her professional fields and enriching his or her practical experience.

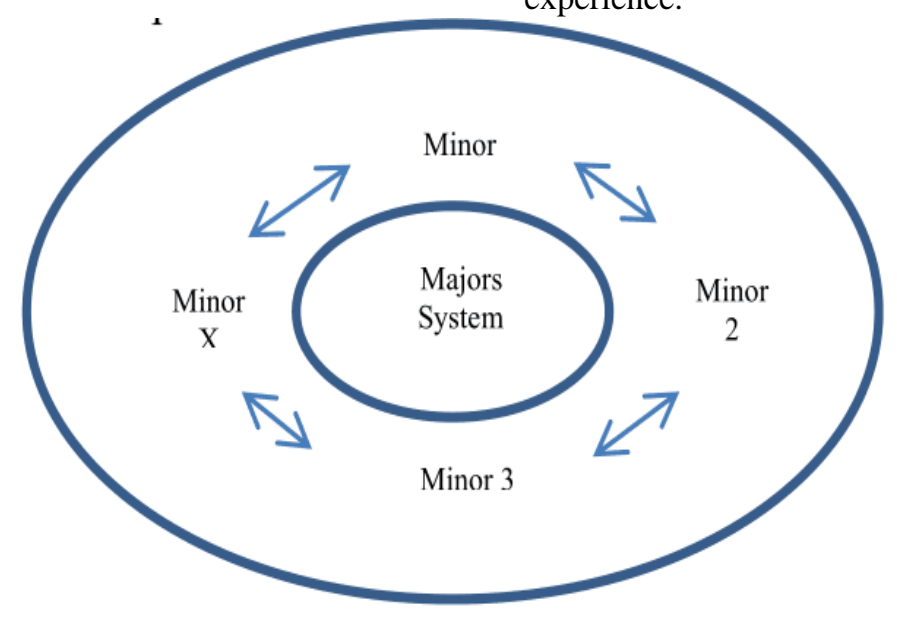

Figure 2 Professional expansion of an educational practitioner.

\subsection{Extensive Practice to Enrich the Experience}

In the fields related to the professional knowledge, more time or energy should be spent in the practical activity so as to obtain a real feeling or perception[4]. In this way, a teacher is able to deeply understand what the reality actually needs and then can perfect himself or herself with a clear purpose. In the meanwhile, as a teacher, he or she is an instructor, a researcher, a preacher or even a performer. He or she ought to have a good communication with either a colleague or a student or an expert, etc. so as to obtain the enlightenment in mind or inspiration in work. Next, in order to foster a mode of mind suitable for the internet thinking, a teacher must master some knowledge \& expertise in the new generation information technology to better interact with the student. All these approaches are much helpful to forge a 
qualified matured teacher with sound mind and rich experience.

\subsection{Further Improving the Knowledge Structure of the Visible Knowledge by Integrating the Knowledge or Expertise or Skills Concerning the Big Data into the Existent Professionals}

The wide use of the big data has dramatically changed the knowledge management whether in the content or in the expressed form or in the data volume \& quality, etc. All these changes need that new approaches or ideas fit for the conditions of the big data ought to be adopted in the aspects of data collecting, processing and analyzing and so on. As an instructor, the practitioner or the preacher of the knowledge must keep on with learning these new approaches or concepts so as to renew the existent knowledge system correspondent with the environment and better manage the knowledge structure. Concretely speaking, the knowledge or expertise or technology compromises the following aspects. In the data mining, seeing that the big data may be structural documents or nonstructural content, a teacher should master some technologies in the concerned field such as artificial intelligence, machine learning, statistics, data bank, cloud computation or visualization[5] and so on. For in the conditions of the big data, with the support of the artificial intelligence, the knowledge management system is endowed with the smart thinking and able to produce and analyze the knowledge automatically. At the same time, the huge volume of the information under the big data requires new tools with a fast speed like cloud computing, etc. to process the data, so the knowledge management system is sure to run at the same speed, too so that it can be renewed in time and go fluently. Besides, because of the diversification of the data such as structural, semistructural and non-structural forms faced by the knowledge management, an educational practitioner must be familiar with the concerned tool like visualization, etc. in order to process various styles of information efficiently in the course of managing his or her knowledge structure, too.

\subsection{Enriching the Existent Professional Knowledge Content with Modern Educational Technology}

Traditionally, the educational technology usually means the approach to design, develop, share, manage and assess the educational process and outcome. Its expressed form, mostly relies on the paper, but the modern educational technology is so diversified that the knowledge can be recorded either in text or in audio or in video or in picture and so forth[6]. In this way, the correspondent knowledge management becomes more and more complicated. An educational practitioner must be skilled at using these modern educational tools so as to absorb the information that he or she needed and to be able to understand the knowledge gathered in different angles before obtaining reasonable explanation. In the meantime, owing to the change of the information retrieval in the knowledge management system under the big data, an educational practitioner should master such kind of skills as the search engine so as to fast, directly obtain the wanted information. This is quite different from the traditional way like notes, book marks or cards, etc. Nowadays, the modern educational technology has been giving much convenience to the teacher for the aim of expanding his or her professional knowledge system.

\subsection{Switching the Knowledge Among Various Professionals by Practical Teaching \& Researching}

As the people's production \& life is advancing fast under the big data, the requirements to the compound skilled personnel with trans-professional knowledge and skills from the society becomes more and more urgent. Also, many students show lots of interests to the knowledge of different disciplines and professionals. To meet the need of these actual situations, the educational practitioner is bound to expand his or her professional. Otherwise, he or she may lose the competitive forces in the market of the human resources. In the conditions of the big data, it is feasible to extend the professional because numerous media or platforms such as mobile terminals, network learning centers, etc. have been set up and provided much convenience for the teacher to train himself or herself in the different disciplines or professionals. At the same time, it is of high possibility for an educational practitioner to extend the professional since a teacher's work concerns multiple disciplines or professionals. The teacher's 
comprehensive competency is the outcome of integrating various professionals or disciplines. Moreover, the national authorities like National Educational Department and Financial Department, etc. have issued the concerned documents[7] to promote the advancement of the cross-disciplines and the trans-professionals. In the near future, these obstacles that do no good to the extension of the professional in the aspects of the professional or discipline configuration, faculty evaluation and so forth are sure to be removed. It is high time for every teacher or educational practitioner to make a global plan for his or her career in the professional. During the integration of the various professionals or disciplines, learning and teaching are valid approaches. The student's question or the aspiration to the knowledge will drive a teacher to further explore his or her knowledge. Another effective way is to do the research based on the topic around the major of an educational practitioner. Usually, an academic dissertation about the social or economic issue may relate to all aspects of science, technology, management, etc. When you compose the paper, you are sure to consult lots of the concerned documents and to be engaged in the social practice. By pondering into these documents and social practical activities, you can be enlightened and some inspiration comes into your mind. Thus, your new ideas are formed in the paper, which can irradiate the other people's mind and taught to the student, too. In one word, the practical teaching, learning and research are the important track to the switch of different professionals or disciplines.

\subsection{Tempering the Digital Mind During the Professional Expansion Based on the Knowledge Management Under the Big Data}

The extensive application of the big data in the educational field is changing the content and approaches of the teaching \& learning. The educational practitioner must change his or her thinking mode mostly based on the retrospective mind as soon as possible into the digital one on the base of the prospective mind. With the support of the big data, the content of the teaching \& learning like the course system setup and courseware, etc. becomes more foresighted, because the correspondent platform of the big data is competent to provide sufficient information or messages needed in the market for the planning of the course setup and for the design of the courseware. In the aspect of the teaching method, the smart platform for the teaching \& learning can do many benefits to improve the teaching \& learning model through the courses generated by the self-adaptive network system, etc. according to the real data during the teaching \& learning. These benefits brought by the big data are helpful to raise both the student's learning outcome and the teacher's teaching performance. To make a full use of the big data tool, it is essential for the educational practitioner to temper his or her digital mind so as to better manage the professional knowledge during the professional expansion.

\subsection{Perfecting the Proper Platform to Expand the Professionals by Further Developing the Knowledge Management System Able to Matching the Big Data}

Since the educational practitioner's professional expansion concerns the obtainment, storage, use and renewal of the knowledge, it is quite essential for a teacher to construct the proper platform to extend his or her professional knowledge on the base of the knowledge management under the big data. The setup of the personal knowledge warehouse is one of the useful ways. First, a teacher must go up with the progress in the science, technology and society and find the links between the progress and the job. According to the job requirements, the work to make the held knowledge systematic should be done so as to find which kind of the knowledge is in short when he or she is engaged in the work. In this method, he or she is able to formulate an overall plan to learn for the purpose of promoting the professional expansion. Then, the existent visible knowledge ought to be passed to the student or to the other persons needing it. In this course of the knowledge inherit, the other people may be enlightened in their mind and change their way of conduct. This is a process from the visible knowledge into the invisible one. The following is that a teacher needs to keep on with finding, analyzing and solving the problem when he or she teaches or communicates with the other people, by which he or she can have a deep understanding of the relative professional development such as features, tendency, advantages, etc. In this course, he or she has undergone a stage from the invisible knowledge to the visible one, because he or she may share his or her point of view about some professional topic or compose the concerned thesis on a certain professional topic. In the conditions of the big data, all these approaches 
in managing the knowledge are numerous enough for a teacher to extend his or her professional knowledge only if he or she is willing to.

\section{CONCLUSION}

All in all, it is not an easy job to be an educational practitioner in the conditions of the wide use of the big data. He or she can well accomplish his or her work only on the base of successfully acting as an inheritor, elocutionist, thinker, knowledge generator and so on. To play these roles, the educational practitioner must keep on with expanding his or her professionals around the major so as to establish a solid professional knowledge system. What's more, it is insufficient for him or her only to have such system. He or she is bound to turn this system into a mechanism so that the knowledge may be able to be accessed freely under the big data. To reach this aim, a better knowledge management for the educational practitioner is a half way to the success.

\section{AUTHORS' CONTRIBUTIONS}

This paper is independently completed by Zhihong Li.

\section{ACKNOWLEDGMENTS}

The paper is funded by the Discipline Group of the Integrative Management Between Economy and Industry in the City Circle, by the Wuhan Studies Institute, Hubei, China (IWHS20172001), and by Research Center on the Development of the Manufacturing Industry of the Wuhan City Circle, China (wz201607).

\section{REFERENCES}

[1] https://baike.baidu.com/item/\%E7\%9F\%A5\% E8\%AF\%86\%E7\%AE\%A1\%E7\%90\%86/120 079 ?fr=aladdin.

[2] Gan Xiao. Grave Influence of the Big Data to the Knowledge Management. http://www.itjspx.com/ITjisuanji/3838.html, Dec. 5, 2020.

[3] Ze Wu. Functions and Method Innovation of the Knowledge Management in the Times of the Big Data. A Guide to the Library Information. 1(01), 2016. Pp110-112.
[4] Guiqin Zhu. On the Teacher's Knowledge Management. Teaching \& Learning Management. 2006(12). Pp17-19.

[5] https://www.21ks.net/lunwen/zsgllw/108574.h tml.

[6] Shen Yang. Analysis on the Influence of the Modern Educational Technology to the Teacher's Knowledge Management. https://www.21ks.net/lunwen/zsgllw/150666.h tml.

[7] Mechanism Problems Are to Be Solved to Develop the Trans-discipline Professionals in China. https://www.sohu.com. 